\title{
Use of Evidence-Based Survey Methods to Explore Early Elementary School Teachers' Approaches to Managing Student Anxiety
}

\author{
Richard D. Birnbaum ${ }^{1}$, Sara E. Witmer ${ }^{1} \&$ John S. Carlson ${ }^{1}$ \\ ${ }^{1}$ School Psychology Program (Counseling, Educational Psychology, and Special Education), Michigan State \\ University, East Lansing, MI, USA \\ Correspondence: John S. Carlson, School Psychology Program (Counseling, Educational Psychology, and \\ Special Education), Michigan State University, East Lansing, MI, USA. E-mail: carlsoj@msu.edu
}

Received: December 11, 2016

Accepted: December 23, 2016 Online Published: January 3, 2017

doi:10.5539/jedp.v7n1p123

URL: http://dx.doi.org/10.5539/jedp.v7n1p123

\begin{abstract}
The purpose of this study was to describe and explore early elementary school teachers' practices with regard to addressing student anxiety, focusing on the types of anxiety-reducing strategies they teach in their classes, the level at which they teach them (i.e., on an individual, small group, or whole class level), and the nature of the approach they use (i.e., proactive or reactive). Using a modified version of Tailored Design Methodology (TDM; Dillman, Smyth, \& Christian, 2014), survey results (N=190 teacher participants; 64\% response rate) indicated that almost two-thirds $(66 \%)$ of teachers affirmed that student anxiety was impacting their classrooms. Almost all teachers (i.e., 90\%) acknowledged teaching multiple anxiety-reducing strategies to their students, contrary to expectations. Survey participants most commonly reported teaching strategies to the whole class, as opposed to teaching strategies to small groups of students or to students on an individual basis. Use of reactive, as opposed to proactive approaches to teaching these strategies were more often reported. Implications are provided for how school personnel can support teachers in using a more proactive approach and ensuring that targeted instruction is available for students with more intensive needs.
\end{abstract}

Keywords: anxiety, children, intervention, school, teachers

\section{Introduction}

Despite the numerous mental health challenges that children and adolescents face, there are regrettably few available resources to meet the overwhelming need; mental health professionals are in serious demand (Albee, 2006). The inability to meet the scope of the problem suggests that mental health prevention efforts must be undertaken (Donovan \& Spence, 2000). Prevention is particularly important to reduce the incidence of anxiety disorders which are the most widespread mental health disorders in childhood and adolescence with prevalence estimates ranging between 2\%-27\% (Sulkowski, Joyce, \& Storch, 2012). Anxiety experienced during childhood and adolescence can adversely impact physical, emotional, and social functioning (Rockhill et al., 2010). It is linked to dysfunction within family relationships, school environments, and peer interactions (Rapee, Schniering, \& Hudson, 2009; Wood, 2006).

Experts contend that it is often difficult to treat mental illness after the fact, suggesting it is much more effective to prevent mental health challenges rather than try to manage them after they have manifested (Doll \& Cummings, 2008; Donovan \& Spence, 2000; Kendall, Settipani, \& Cummings, 2012; National Association of School Psychologists, 2009). Thus, a focus on mental health prevention, rather than providing treatment solely after illnesses become established is both practically more resource efficient and clinically more effective. Further, timing, or when to begin strategy implementation is an important consideration with prevention interventions (Donovan \& Spence, 2000). As experts reason, younger children have more neuroplasticity, meaning that many unwarranted behaviors are more easily altered at an earlier stage in development (Hirshfield-Becker \& Biederman, 2002).

Schools have been proposed as an ideal place to prevent mental health challenges (Strein, Hoagwood, \& Cohn, 2003). They offer convenient locations to serve large numbers of children who may not have access to mental health services (Adelman \& Taylor, 2012; McLoone, Hudson, \& Rapee, 2006). Moreover, schools provide an authentic setting for children to practice coping skills with staff and administrators who are ideally situated to 
supervise children and monitor their behavior (McLoone et al., 2006). Teachers can play a major role in helping build social and emotional protective factors within children who are at-risk for future developmental challenges (Jennings \& Greenberg, 2009).

Cognitive Behavioral Therapy (CBT) - a hybrid method that incorporates cognitive, behavioral, emotion-centered, and social strategies to affect psychological change-is recognized as the primary evidence-based psychological treatment for childhood anxiety disorders and symptoms (Seligman \& Ollendick, 2011). CBT has been effectively delivered in both individual and group formats (Silverman, Pina, \& Viswesvaran, 2008), with evidence showing positive effects with children as young as preschool age (Minde, Roy, Bezonsky, \& Hashemi, 2010). Although many CBT programs are implemented by trained psychological professionals, some CBT programs utilize more basic cognitive-behavioral techniques and can be implemented by other professionals, such as classroom teachers or school staff (Forman \& Barakat, 2011). Ultimately, the flexibility inherent in CBT-based programs makes it possible to deliver effective treatments in environments, such as schools, where resources are lacking but still needed (Mychailyszyn et al., 2011). For instance, research-based programs implemented in schools, such as the individual or small group designed CBT-based Coping Cat program (Kendall \& Hedtke, 2006) and the CBT-based FRIENDS program (Barrett, Lowry-Webster, \& Turner, 2000), which is intended to be implemented at the classroom level, have been shown to be successful in helping students learn to manage anxiety (Barrett, Farrell, Ollendick, \& Dadds, 2006; Kendall, 1994). When properly trained, teachers have been able to successfully implement prevention programs for mental health, including programs such as FRIENDS (Barrett et al., 2006). The FRIENDS program involves teaching students specific steps for coping with their anxiety. Each step is represented by a letter in the program title as follows: "F" stands for "feeling worried", "R" stands for "relax and feel good", "I" stands for "inner thoughts", "E" stands for "explore plans of action", "N" stands for "nice work, reward yourself", "D" stands for "don't forget to practice", and "S" stands for "stay cool" (Barrett \& Turner, 2001). In teaching these coping steps, teachers lead students through relaxation techniques, cognitive restructuring, attention exercises; family and peer supports are also addressed through the program.

There are often numerous barriers to program implementation in schools, despite the various aforementioned positive aspects and outcomes (Greenberg, 2010). For example, social-emotional program implementation can be time consuming (i.e., required training of staff and associated coordination efforts), and may be a lower priority for administrators than directly addressing academic deficiencies. These barriers may contribute to a lack of sufficient program buy-in and poor implementation fidelity (Adelman \& Taylor, 2012). Despite these challenges, teachers are ultimately responsible for addressing children's mental health needs on a daily basis, due to the influence that poor mental health can have on academic progress (Jennings \& Greenberg, 2009; Koller \& Bertel, 2006).

Unfortunately teachers receive minimal applied mental health training at the pre-service level (Jennings \& Greenberg, 2009; Koller \& Bertel, 2006). With regard to internalizing disorders, such as anxiety, Bryer and Signorini (2011) found that pre-service teachers' experience and knowledge of suffering students occurred mainly unintentionally, such as through personal exposures with family and friends with anxiety disorders, through information acquired in popular media, and through chance experiences with students in their practicum sites. Further, practicing teachers themselves have reported heavy exposure to students with mental health challenges, but limited knowledge for working with them. For instance, in a study examining early childhood and elementary school teachers' $(n=292)$ perceptions of student mental health challenges, $75 \%$ reported that they either taught or referred a student with mental health challenges to school mental health professionals, and $76 \%$ indicated that they believed anxiety problems were major mental health challenges in their classrooms (Reinke, Stormont, Herman, Puri, \& Goel, 2011).

Apart from situations in which researchers have studied the implementation of specific classroom-based anxiety prevention programs, research is not readily available to more generally describe how teachers are currently addressing student anxiety in their classrooms. Experts contend that current school policies for addressing mental health concerns (e.g., anxiety) are likely rooted in a more traditional, "wait-to-fail" philosophy, with less of a prevention-focused mind-set (Albers, Glover, \& Kratochwill, 2007). Jones and Bouffard (2012) assert that everyday Social Emotional Learning (SEL) practices integrated into the curriculum are likely unplanned and not research driven. For those schools that do provide a range of SEL practices, Jones and Bouffard (2012) maintain that supports are likely in the form of universal programming or individually focused instruction. 
The descriptive study by Reinke et al. (2011) highlighted that teachers felt unprepared to manage students with mental health challenges in their classrooms. Building off of this research, the current study focuses on one area of student mental health, anxiety, in order to identify ways in which teachers report helping students build skills for managing their symptomology.

Gaining this information may help to (a) better understand the current state of teacher classroom support for students presenting with anxiety, and (b) inform the work of school mental health staff who are interested in helping teachers most effectively address student anxiety at the classroom level. Specific research questions addressed and associated hypotheses include the following:

1) To what extent do teachers (a) report that student anxiety is impacting the classrooms, (b) report using published programs to teach strategies for anxiety in their classrooms, and c) report teaching strategies that are aligned with CBT-based approaches for managing anxiety?

2) How are these strategies taught to students (i.e., whole class instruction, small group instruction, individualized instruction)?

3) Do teachers teach these strategies preventatively or reactively (i.e., prior to or in reaction to students' display of anxiety)?

Based upon the aforementioned research by Reinke et al. (2011), and insights derived from experts (e.g., Albers et al., 2007; Jones \& Bouffard, 2012), we hypothesized that teachers would report student anxiety to be impacting their classrooms, teach a limited number of CBT-based strategies, and most frequently teach them on an individual level in a reactive manner.

\section{Methods}

\subsection{Participants and Setting}

Following approval of the research procedures by an institutional review board, 299 general education teachers were invited to participate in a survey and 190 participated (response rate of 64\%). To help understand the characteristics of the sample surveyed, a summary of demographic data collected is presented. Ninety-five percent of the responding teachers identified as White/Caucasian, 3\% identified as African American, 1\% identified as Asian American, and 1\% identified as Hispanic American. Seventy percent of respondents reported having a master's degree, and 30\% reported having a bachelor's degree. Sixty-eight percent of teachers reported having more than $10+$ years of experience, $32 \%$ reported having between zero and nine years of experience. Testing for single proportions revealed no significant differences between these demographic characteristics and those associated with teachers in the corresponding state for the academic year 2011-2012 as reported by the U.S. Department of Education (National Center for Education Statistics, 2013a, 2013b). However significant differences were identified between the percentages of teachers reporting as males $(3 \%)$ and females $(96 \%)$ in our study compared to the percentages of male $(24 \%)$ and female $(76 \%)$ elementary school teachers for the state, $z=6.978, p<.001$, and $z=6.48, p<.001$ as reported by the National Education Association (2014).

Respondents consisted of kindergarten (33\%), first grade (32\%), and second grade (35\%) general education teachers. They served school districts in 34 of 83 counties in the entire state in which the study was located. Twenty-eight percent of teachers reported teaching in counties with a low proportion of students receiving free and reduced priced lunch (FRL), 25\% reported teaching in counties with a moderate proportion of students receiving FRL, and 37\% reported teaching in counties with a high proportion of students receiving FRL. Ten percent of teachers did not report the county in which they worked, and so the proportion of students with FRL could not be determined.

\subsection{Procedure}

Teachers were recruited from within a Midwestern state. All public schools in the state with students in kindergarten, first, and second grades were arranged into three groups-low (0-33\%), medium (34\%-66\%), and high (67\%-100\%) - based upon percentages of students who received FRL. This was done to obtain a representative sample of teachers from low, medium, and upper income communities. The percentages of students receiving FRL were determined from data reported in 2013 via the Michigan Department of Education (Center for Educational Performance and Information, 2014). One hundred schools were then randomly selected so that 33 schools were from the low FRL group, 34 from the medium FRL group, and 33 from the high FRL group. Teachers' names and the grade level they taught were then ascertained through publically displayed websites. Three teachers (i.e., one kindergarten, one first grade, and one second teacher) were then randomly selected to 
participate from each school. In situations where teacher grade level or teacher names were not publically displayed, a different school was randomly selected from the same FRL group.

All teachers were contacted via postal mail and were asked to participate using a modified version of the Tailored Design Methodology (TDM; Dillman, Smyth, \& Christian, 2014). The TDM strives to build a positive social exchange with participants and involves customizing survey methods to each specific situation in accordance with the audience, available funding, and necessary time frame for response (Dillman et al., 2014). It has been shown to yield response rates above 50\% (Chidlow, Ghauri, Yeniyurt, \& Cavusgil, 2015; Dillman et al., 2014). For the current study, three mail-based contacts were made with potential participants. The first included a survey invitation letter, a \$2 unconditional incentive and an envelope and paid postage for survey return. Research on survey incentives has shown prepaid cash incentives to result in greater rates of participation than just promised incentives (Dillman et al., 2014; Singer \& Ye, 2013). The second mailing consisted of a follow-up postcard and the third and final mailing sent to all 299 teachers contained a final reminder letter and a replacement survey (see Table 1 for return rate data for the three mailings).

Table 1. Return rate for the three mailings

\begin{tabular}{lcccc}
\hline \multicolumn{1}{c}{ Mailing } & Mailing Period & $\begin{array}{c}\text { Surveys Received } \\
\text { (n) }\end{array}$ & \% of total & Total Surveys Received \\
& & 21 & $11 \%$ & 21 \\
\hline Mailing 1: Survey & $1 / 20 / 15$ to $1 / 26 / 15$ & 38 & $20 \%$ & 59 \\
Mailing 2: Postcard & $1 / 27 / 15$ to $2 / 3 / 15$ & 132 & $69 \%$ & 191 \\
Mailing 3: Survey & $2 / 4 / 15$ & & \\
\hline
\end{tabular}

\subsection{Measures}

The survey consisted of three sections: teacher demographics, teacher beliefs about anxiety and anxiety program implementation history, and current teacher practices. Questions were created through a process that included multiple revisions as a result of feedback garnered from other researchers and elementary school teachers. Evidence for content validity was derived using the anxiety, mental health prevention, and CBT literature as guides for survey content. Two university professors with expertise in student anxiety reviewed item content and provided suggested revisions. The survey was then piloted with four teachers in a local elementary school district to obtain feedback on question clarity.

\subsubsection{Teacher Demographics}

Teachers were asked to provide individual demographic information including current instructional grade level, years of teaching experience, degree attainment, gender, race, and county where they taught. Data obtained from questions in this section were analyzed using descriptive statistics. Of note, to maintain participant anonymity, participants were only requested to provide the name of the county in which they taught. This was done to establish a general estimate of the socioeconomic status (SES) of their school communities. County-wide FRL data (i.e., the percentage of students receiving either a free or reduced priced lunch) was then gathered from each county (Kids Count Data Center, 2015; Michigan League for Public Policy, 2015). County data were then ranked in order by FRL percentage and organized into thirds, consisting of low, medium, and high categories. It should be acknowledged that using free and reduced lunch percentages as an indicator of socioeconomic status is widely used in school-based studies despite numerous limitations (Harwell \& LeBeau, 2010).

\subsubsection{Program Implementation History}

The second section of the survey included items concerning teachers' perceptions of how anxiety impacts their classroom and items related to present and past implementation of published programs addressing student anxiety. Data obtained from questions in this section were analyzed using descriptive statistics.

\subsubsection{Current Teacher Practices}

(1) Number of CBT-based strategies taught. Teachers were asked to respond either yes or no as to whether they taught seven specific strategies for managing anxiety to their students. If they answered no for a strategy, they were prompted to respond to the next CBT-based, core strategy question. Sum scores (0-7) for each teacher were then determined to describe each teacher's strategy use. 
Items corresponding to teachers' use of CBT-based strategies were adapted to address the following core CBT components: psychoeducation, relaxation training, exposures, cognitive restructuring, modifying contingencies, and skills training (Suldo \& Ogg, 2014). For the sake of survey question clarity, it was decided that teachers' use of relaxation training should be split into two different questions: one focused on cognitive relaxation and one focused on physical relaxation. Thus, seven total questions were developed addressing the use of the six aforementioned CBT-based components. See Table 2 for the specific questions used.

Table 2. Teachers' responses to teaching core CBT-based strategies $(\mathrm{N}=190)$

\begin{tabular}{|c|c|c|}
\hline \multirow[t]{2}{*}{ Question } & \multicolumn{2}{|c|}{$\underline{\text { Yes }}$} \\
\hline & $\mathrm{n}$ & $\%$ \\
\hline $\begin{array}{l}\text { Do you teach individual students about anxious thoughts, feelings, and behaviors (e.g., expectation of negative } \\
\text { outcomes, butterflies in their stomachs, running away and hiding) and how to identify these in themselves? }\end{array}$ & 121 & 64 \\
\hline $\begin{array}{l}\text { Do you teach mental relaxation exercises for anxiety (e.g., breathing, meditation) to help students become } \\
\text { aware of/reduce anxious thoughts in their minds/bodies? }\end{array}$ & 110 & 58 \\
\hline $\begin{array}{l}\text { Do you teach physical relaxation exercises for anxiety (e.g., yoga, stretching, dancing or jumping up and down) } \\
\text { to help students become aware of/reduce tension in their bodies? }\end{array}$ & 122 & 64 \\
\hline $\begin{array}{l}\text { Do you use imaginary scenarios and/or role-play exercises with your students in order to teach them how to } \\
\text { manage stressful situations (e.g., speaking in front of class, asking a new child to play)? }\end{array}$ & 130 & 68 \\
\hline $\begin{array}{l}\text { Do you teach and encourage students to challenge their anxious thoughts (e.g., "My parents will forget to pick } \\
\text { me up from school today.") and encourage more positive, confident thinking (e.g., "My parents always pick me } \\
\text { up everyday. They'll be here today!) }\end{array}$ & 119 & 63 \\
\hline $\begin{array}{l}\text { Do you teach students to appreciate and reward themselves for the efforts/actions they take in addressing their } \\
\text { anxieties? }\end{array}$ & 98 & 52 \\
\hline $\begin{array}{l}\text { Do you teach students a specific step-by-step, problem solving process or method to help them develop the } \\
\text { skills to find positive solutions for reducing or eliminating particular anxieties? }\end{array}$ & 64 & 34 \\
\hline
\end{tabular}

(2) Strategy teaching by level. If teachers answered yes to teaching a specific CBT-based strategy, they were then asked whether they taught the given strategy on a whole class, small group, or individual level. Respondents had the option to select one, two, or all three levels. Three separate sum scores were created for each responding teacher representing the number of strategies endorsed at the (a) whole class, (b) small group, and (c) individual student level.

(3) Proactive and reactive strategy implementation. If teachers answered yes to indicate teaching a specific CBT-based strategy, information on the use of proactive (i.e., meaning that they planned a lesson ahead of time to teach the strategy) and reactive (i.e., meaning they taught the strategy spontaneously in response to a particular classroom situation) approaches was also gathered. Respondents had the option to select one or both implementation types. Two sum scores were created for each responding teacher. The first indicated the number of strategies teachers reported using in a proactive manner and the second indicated the number of strategies teachers reported using in a reactive manner.

\subsection{Missing Data}

Missing data were evident for just $1 \%$ of possible responses across values collected for analysis in the current study. Missing data imputation was based upon logical rules (Gelman \& Hill, 2007). In cases where teachers failed to report the level and implementation type for a strategy that they reported using, the associated sum scores were calculated using the remaining items on which they did report information. 


\section{Results}

\subsection{Impact of Anxiety on the Classroom}

Teachers' were asked to provide information about whether they believed student anxiety had an influence within their classrooms. Sixty-six percent of teachers reported that they agreed or strongly agreed that student anxiety influenced the classroom setting. A total of $14 \%$ reported that they neither agreed nor disagreed that student anxiety impacted the classroom. A total of $20 \%$ or 1 in 5 teachers indicated that anxiety did not impact the classroom.

\subsection{Program Implementation Practices}

When asked whether or not they had used a specific program (e.g., FRIENDS) to address student anxiety with their whole class, $87 \%$ of teachers (165) reported they had not. For the $13 \%$ (25 teachers) who reported they had used a program and were asked to provide a specific name of that program, 16 teachers reported they used Second Step, with two teachers reporting that school counselors - not the teachers themselves - taught Second Step to their classrooms. The remaining teachers either specified programs not typically associated with addressing anxiety (e.g., CHAMPS), or reported that school counselors or social workers taught lessons - not the teachers themselves.

\subsection{Number of CBT-Based Strategies Taught}

On average, teachers reported teaching four of the seven possible strategies $(M=4.02, S D=1.92)$. Nine teachers (4.7\%) reported teaching zero strategies, 10 teachers $(5.2 \%)$ reported teaching one strategy, 22 teachers $(11.6 \%)$ reported teaching two strategies, 37 teachers (19.5\%) reported teaching three strategies, 34 teachers $(17.9 \%)$ reported teaching four strategies, 26 teachers $(13.7 \%)$ reported teaching five strategies, 31 teachers (16.3\%) reported teaching six strategies, and 21 teachers (11.1\%) reported teaching seven strategies. See Table 2 for specific information on the percentage of teachers reporting use of each strategy examined. Teachers most frequently $(68 \%)$ reported using imaginary scenarios and role-playing exercises to help students practice managing their anxiety in different stressful situations. They least frequently (34\%) reported teaching a step-by-step problem solving process with their students.

\subsection{Strategy Teaching by Level}

Using discrete count data as dependent variables necessitated the use of a Poisson distribution to perform the remaining analyses (Dunteman \& Ho, 2006). Given that the count data lacked independence, a mixed model was used to account for the dependency. Moreover, to confirm that normality assumptions were met, residual data points were examined with histograms and stem and leaf plots. These visual depictions indicated that residual data points satisfactorily met these assumptions.

Estimates obtained through the use of a Poisson Regression Mixed Model showed the mean number of strategies teachers reported teaching on an individual level to be $1.9(S E=.13)$. The mean number they reported teaching on a small group level was .6 $(S E=.07)$, and the mean number they reported teaching on a whole class level was 3.0 $(S E=.17$; see Tables 3 and 4 for information on strategy teaching by level). A significant difference was found for implementation level $(p<.001)$. On average, the mean number of strategies teachers reported teaching on a small group level was $80 \%$ less than those they reported teaching on a whole class level. The mean number of strategies teachers reported teaching on an individual level was $40 \%$ less than those they reported teaching on a whole class level. 
Table 3. Poisson regression mixed model means, standard errors, and Confidence Intervals (CI) for strategy teaching by level and proactive or reactive strategy teaching implementation

\begin{tabular}{lccc}
\hline \multicolumn{1}{c}{ Variable } & M & SE & 95\% CI \\
\hline Strategy Teaching By Level & & & {$[1.6,2.2]$} \\
Individual & 1.9 & .13 & {$[.5, .7]$} \\
Small Group & .6 & .07 & {$[2.7,3.4]$} \\
Whole Class & 3.0 & .17 & {$[1.5,1.9]$} \\
Proactive or Reactive Strategy Teaching & & .12 & .18 \\
Proactive & 1.7 & $3.6,4.3]$ \\
Reactive & 3.9 & & \\
\hline
\end{tabular}

Table 4. Poisson regression mixed model coefficients, t-scores, p-values, exponential coefficients, and Confidence Intervals (CI) for strategy teaching by level and proactive or reactive strategy teaching implementation

\begin{tabular}{|c|c|c|c|c|c|c|}
\hline & Coefficient & $\mathrm{SE}$ & $\mathrm{t}$ & $\mathrm{p}$ & $\begin{array}{c}\text { Exp } \\
\text { (Coefficient) }\end{array}$ & $95 \% \mathrm{CI}$ \\
\hline \multicolumn{7}{|c|}{ Strategy Taught By Level } \\
\hline Intercept & 1.113 & .06 & 19.86 & $<.001$ & 3.0 & {$[2.7,3.4]$} \\
\hline Individual & -.485 & .09 & -5.34 & $<.001$ & .6 & {$[.5, .7]$} \\
\hline Small Group & -1.659 & .14 & -11.84 & $<.001$ & .2 & {$[.1, .3]$} \\
\hline \multicolumn{7}{|c|}{ Strategy Implementation } \\
\hline Intercept & 1.364 & .05 & 29.18 & $<.001$ & 3.9 & {$[3.6,4.3]$} \\
\hline Proactive & -.846 & .09 & -9.92 & $<.001$ & .4 & {$[.4, .5]$} \\
\hline
\end{tabular}

Note. "Whole Class" and "Reactive" used as the references for the intercepts.

\subsection{Proactive and Reactive Strategy Implementation}

Further applying a Poisson Regression Mixed Model analysis showed that the mean number of strategies that teachers reported teaching in a proactive manner was $1.7(S E=.12)$, whereas the mean number that teachers reported teaching in a reactive manner was $3.9(S E=.18$; see Tables 3 and 4 for more information on proactive and reactive strategy teaching implementation). A significant difference was found, with teachers reporting teaching strategies $60 \%$ less proactively than reactively $(p<.001)$.

\section{Discussion}

Research has shown that teachers have indicated anxiety as a major concern in their classrooms and the findings of this survey-based study further support the scope of this concern. Almost two-thirds (66\%) of teachers surveyed agreed or strongly agreed that anxiety was impacting their classrooms. When considering this finding within the context of prior research showing that only $34 \%$ of teachers felt they had the skills needed to properly support children with mental health needs (Reinke et al., 2011), questions arise about how teachers are addressing the pervasiveness of anxiety within their classrooms. The purpose of this study was to more closely examine early elementary school teachers' anxiety reduction practices. We explored the types of strategies teachers might be teaching them (i.e., at what level), and the manner in which the strategies were implemented (i.e., proactively vs. reactively).

It was hypothesized that teachers would report limited to no involvement in the use of CBT-based strategies for students with anxiety. Contrary to this expectation, the majority of teachers $(90 \%)$ reported using two or more CBT-based strategies. Additionally, survey responses indicated that teachers used numerous CBT-based strategies in the classroom (an average of four). The most commonly reported strategy was using imaginary 
scenarios and role-play exercises (with $68 \%$ reporting using this strategy). This was a surprising result, particularly given prevailing literature indicating minimal teacher training with regard to student mental health management (e.g., Freeman, Simonsen, Briere, \& MacSuga-Gage, 2014; Jennings \& Greenberg, 2009; Koller \& Bertel, 2006). However, only a small proportion (34\%) of teachers reported teaching a step-by-step problem solving method. This seems to align with the notion that teachers do not typically apply a structured curriculum to address student anxiety. In contrast, in a CBT-based anxiety management program such as Coping Cat, children are taught to use the four-step, problem solving FEAR plan when they experience anxiety in a particular situation - with each letter of the acronym FEAR standing for a different skill they have learned (Kendall \& Hedtke, 2006). The fact that a majority of teachers did not report teaching this type of problem solving process may be an indication that teachers are most comfortable in informally addressing issues of anxiety as they unfold within their classrooms.

It was hypothesized that teachers would report teaching the CBT-based strategies most often on an individual level. Yet, our results showed that teaching strategies on a universal (i.e., whole classroom) level was found to be most common, followed by teaching strategies at the individual level. Teaching strategies at the small group level was the least common. Based on these results, it may be the case that teachers recognize or intuitively sense that all students may benefit from being taught these strategies when certain anxiety-provoking situations arise and are therefore using the strategies on a universal level. Furthermore, for those students who are specifically struggling or in need of additional assistance, individual support is provided. The limited reporting of small group level teaching may be an indication that it is challenging for a classroom teacher to provide small group instruction to students on this topic.

Finally, it was hypothesized that teachers would more commonly report teaching strategies in a reactive as opposed to a proactive manner. The results supported this hypothesis: teachers reported teaching strategies reactively two times more often than they reported teaching strategies proactively. Based on the results of this survey, it appears that teachers often wait to address anxiety until students display anxious behavior within the classroom. In Reinke et al. (2011) teachers reported they felt it more appropriate for school-based mental health staff (e.g., school psychologists, social workers) to teach social-emotional lessons. This finding seems to align with the results from the current study. Although teachers did report teaching multiple CBT-based strategies, they reported doing so in a reactive manner, not proactively planning a lesson ahead of time. Experts advocating a proactive, prevention-based approach to mental health are numerous (e.g., Doll \& Cummings, 2008; Hirshfeld-Becker \& Biederman, 2002; Strein et al., 2003), not only because of the efficacy of addressing challenges before they manifest and become intensified, but also as a way of promoting wellness. A proactive approach can provide students with the skills to manage emotions when anxious situations are presented (Hirshfeld-Becker \& Biederman, 2002).

\subsection{Limitations}

Certain limitations in this study should be acknowledged. Because this study relied on teachers' self-report of their practices, it is possible that these reports do not adequately represent actual practice. Systematic observation and interviews would offer more objective information on teachers' actual teaching of these strategies. Also, the sample is limited to teachers in one state, with the vast majority of teachers acquiring their degree in the state as well (95\%). Pre-service teacher training programs likely differ across states and therefore results may vary in other areas. Additionally, we did not ask teachers to report on the frequency with which they teach each of the various strategies. It may be the case that although many teachers reported teaching the given strategies, they only do so in rare situations. Not reporting frequency also limited our ability to more thoroughly compare and contrast teachers' use of the individual techniques. Furthermore, sampling bias may be present in the current study results given that $36 \%$ of those invited to participate did not respond.

\subsection{Implications for Practice}

Results from this study suggest that teachers perceive student anxiety to be impacting their classrooms and are actively engaging in informal classroom-based approaches to address this anxiety. Further educating teachers about best practices for managing and preventing student anxiety is important, particularly in the absence of adopting formal programs aimed at preventing anxiety in the classroom. Additionally, school personnel (e.g., principals, social workers, school psychologists) might assist teachers in embedding CBT-based exercises for anxiety into already existing academic or social emotional lessons. Though this would not be a comparable substitute for more formalized program implementation (e.g., FRIENDS), it still may help teachers manage and prevent related challenges as well as equip all students with coping skills that can help them be successful in a 
variety of situations. In particular, this could occur in situations where barriers exist to implementing a published evidence-based program.

Teachers appear to target instruction to address anxiety to the whole class, with fewer teachers reporting targeted instruction for small groups and individual students. It may be the case that in many situations, more targeted and individualized instruction is needed. Given teachers' reported lack of knowledge and inadequate training for meeting their students' mental health needs (e.g., Reinke et al., 2011), questions must be raised whether teachers are actually equipped to effectively offer this type of instruction. School-based mental health personnel can play a key role in assisting teachers to both identify related student needs, as well as to help teachers develop targeted interventions for those who are at-risk for heightened levels of anxiety.

Results from this study also indicate that teachers were teaching strategies more reactively than proactively. Teachers should be encouraged by school-based mental health personnel to take a more proactive approach by consulting with them about the benefits of prevention, but also by providing them with the necessary tools to do so (i.e., through best practices training and ongoing support and consultation). Whitley, Smith, and Vaillancourt (2012) suggest that in order to effectively prevent mental health challenges in students, it is vital for teachers to have the understanding, abilities, and mindsets to be successful. They suggest developing teachers' mental health literacy by holding ongoing professional development rather than one-time only workshops, using extant literature to effectively target known teacher knowledge gaps and misperceptions, and creating professional learning communities where teachers can learn and develop their knowledge and skills while collaborating with fellow colleagues.

Overall, given the widespread prevalence of anxiety disorders in childhood (e.g., Rapee et al., 2009) and the significant impact that they can have on immediate and long-term development (e.g., Rapee et al., 2009), including physical, social and emotional functioning (e.g., Rockhill et al., 2010), it is imperative that schools capitalize on opportunities to help those students in need. Teaching in a preventative fashion can be an efficient use of limited resources and advantageous to all students, particularly given the fact that they may experience multiple anxiety-provoking situations at different times in their lives. Learning effective coping strategies could prove highly beneficial for all students. In a school environment, teachers are key to intervention efforts but likely benefit from the support of school psychologists to help develop the necessary skills.

\subsection{Implications for Future Research}

Additional research is needed to better understand teacher practices related to management of student anxiety in their classrooms. In addition, teachers' roles and responsibilities with respect to assessment, consultation, and intervention around student mental health needs warrant additional attention in the literature. Specifically, observation and interview methods may help to further identify how and why teachers are implementing particular practices to address student mental health problems and whether what is reported in this survey-based study would be consistent with their actual/observed day-to-day practices. Moreover, it is important to evaluate how effective each of these practices is in building students' coping skills when implemented by teachers. This study only examined kindergarten, first, and second grade teacher practices. Future research should examine the extent to which teachers at other grade levels are involved in teaching such strategies.

\section{References}

Adelman, H. S., \& Taylor, L. (2012). Mental health in schools: Moving in new directions. Contemporary School Psychology, 16, 9-18.

Albee, G. W. (2006). Historical overview of primary prevention of psychology: Address to the $3^{\text {rd }}$ world conference on the promotion of mental health and prevention of mental and behavioral disorders, September 15-17, 2004, Auckland, New Zealand. The Journal of Primary Prevention, 27, 449-456. http://dx.doi.org/10.1007/s10935-006-0047-7

Albers, C. A., Glover, T. A., \& Kratochwill, T. R. (2007). Where are we, and where do we go now? Universal screening for enhanced educational and mental health outcomes. Journal of School Psychology, 45, 257-263. http://dx.doi.org/10.1016/j.jsp.2006.12.003

Barrett, P. M., \& Turner, C. (2001). Prevention of anxiety symptoms in primary school children: Preliminary results from a universal school-based trial. British Journal of Clinical Psychology, 40, 399-410. http://dx.doi.org/10.1348/014466501163887 
Barrett, P. M., Farrell, L. J., Ollendick, T. H., \& Dadds, M. (2006). Long-term outcomes of an Australian universal prevention trial of anxiety and depression symptoms in children and youth: An evaluation of the Friends program. Journal of Clinical Child and Adolescent Psychology, 35, 403-411. http://dx.doi.org/10.1207/s15374424jccp3503_5

Barrett, P. M., Lowry-Webster, H., \& Turner, C. (2000). FRIENDS program for children: Group leader's manual. Brisbane: Australian Academic Press.

Bryer, F., \& Signorini, J. (2011). Primary pre-service teachers' understanding of students' internalizing problems of mental health and wellbeing. Issues in Educational Research, 21, 233-258.

Center for Educational Performance and Information. (2014). Free and reduced lunch counts [Data File]. Retrieved from http://www.michigan.gov/cepi/0,1607,7-113-21423_30451_36965---,00.html

Chidlow, A., Ghauri, P. N., Yeniyurt, S., \& Cavusgil, S. T. (2015). Establishing rigor in mail-survey procedures in international business research. Journal of World Business, 50, 26-35. http://dx.doi.org/10.1016/j.jwb.2014.01.004

Dillman, D. A., Smyth, J. D., \& Christian, L. M. (2014). Internet, phone, mail, and mixed-mode surveys: The tailored design method (4th ed.). Hoboken, NJ: Wiley.

Doll, B., \& Cummings, J. (Eds.). (2008). Transforming school mental health services: Population-based approaches to promoting the competency and wellness of children. Bethesda, MD: National Association of School Psychologists.

Donovan, C. L., \& Spence, S. H. (2000). Prevention of childhood anxiety disorders. Clinical Psychology Review, 20, 509-531. http://dx.doi.org/10.1016/S0272-7358(99)00040-9

Dunteman, G. H., \& Ho, M. H. R. (2006). An introduction to generalized linear models. Thousand Oaks, CA: Sage Publications, Inc. http://dx.doi.org/10.4135/9781412983273

Forman, S. G., \& Barakat, N. M. (2011). Cognitive-behavioral therapy in the schools: Bringing research to practice through effective implementation. Psychology in the Schools, 48, 283-296. http://dx.doi.org/10.1002/pits.20547

Freeman, J., Simonsen, B., Briere, D. E., \& MacSuga-Gage, A. S. (2014). Pre-service teacher training in classroom management: A review of state accreditation policy and teacher preparation programs. Teacher Education and Special Education, 37, 106-120. http://dx.doi.org/10.1177/0888406413507002

Gelman, A., \& Hill, J. (2007). Data analysis using regression and multilevel/hierarchical models. New York: Cambridge University Press.

Greenberg, M. T. (2010). School-based prevention: Current status and future challenges. Effective Education, 2, 27-52. http://dx.doi.org/10.1080/19415531003616862

Harwell, M., \& LeBeau, B. (2010). Student eligibility for a free lunch as an SES measure in education research. Educational Researcher, 39, 120-131. http://dx.doi.org/10.3102/0013189X10362578

Hirshfeld-Becker, D. R., \& Biederman, J. (2002). Rationale and principles for early intervention with young children at risk for anxiety disorders. Clinical Child and Family Psychology Review, 5, 161-172. http://dx.doi.org/10.1023/A:1019687531040

Jennings, P. A., \& Greenberg, M .T. (2009). The prosocial classroom: Teacher social and emotional competence in relation to student and classroom outcomes. Review of Educational Research, 79, 491-525. http://dx.doi.org/10.3102/0034654308325693

Jones, S. M., \& Bouffard, S. M. (2012). Social and emotional learning in schools: From programs to strategies. Social policy report. Society for Research in Child Development, 26, 1-33.

Kendall, P. C. (1994). Treating anxiety disorders in children: Results of a randomized clinical trial. Journal of Consulting and Clinical Psychology, 62, 100-110. http://dx.doi.org/10.1037/0022-006X.62.1.100

Kendall, P. C., \& Hedtke, K. A. (2006). Cognitive-behavioral therapy for anxious children: Therapist manual (3rd ed.). Ardmore, PA: Workbook.

Kendall, P. C., Settipani, C. A., \& Cummings, C. M. (2012). No need to worry: The promising future of child anxiety research. Journal of Clinical Child and Adolescent Psychology, 41, 103-115. http://dx.doi.org/10.1080/15374416.2012.632352 
Kids Count Data Center. (2015). Students eligible for free or reduced priced lunch. Retrieved from http://datacenter.kidscount.org/data/Tables/1672-students-eligible-for-free-or-reduced-priced-lunch?loc $=24$ \&loct $=5 \#$ ranking $/ 5 /$ any $/$ true/36/any/

Koller, J. R., \& Bertel, J. M. (2006). Responding to today's mental health needs of children, families and schools: Revisiting the preservice training and preparation of school-based personnel. Education \& Treatment of Children, 29, 197-217.

McLoone, J., Hudson, J. L., \& Rapee, R. M. (2006). Treating anxiety disorders in a school setting. Education \& Treatment of Children, 29, 219-242.

Michigan League for Public Policy. (2015). Mapping the facts. Retrieved from http://www.mlpp.org/resources/county-fact-sheets

Minde, K., Roy, J., Bezonsky, \& Hashemi. (2010). The effectiveness of CBT in 3-7 year old anxious children: Preliminary data. Journal of Canadian Academy of Child and Adolescent Psychology, 19, 109-115.

Mychailyszyn, M. P., Beidas, R. S., Benjamin, C. L., Edmunds, J. M., Podell, J. L., Cohen, J. S., \& Kendall, P. C. (2011). Assessing and treating child anxiety in schools. Psychology in the Schools, 48, 223-232. http://dx.doi.org/10.1002/pits.20548

National Association of School Psychologists. (2009). Appropriate behavioral, social, and emotional supports to meet the needs of all students. Bethesda, MD: Author.

National Center for Education Statistics. (2013a). Highest degree earned, years of full-time teaching experience, and average class size for teachers in public elementary and secondary schools, by state: 2011-2012 [data table 209.30]. Retrieved from https://nces.ed.gov/programs/digest/d13/tables/dt13_209.30.asp

National Center for Education Statistics. (2013b). Total number of public school teachers and percentage distribution of school teachers, by racelethnicity and state: 2011-2012 [table 1]. Retrieved from https://nces.ed.gov/surveys/sass/tables/sass1112_2013314_t1s_001.asp

National Education Association. (2014). Estimated number of instructional staff members in public elementary and secondary schools by type of position, 2013-2014 [summary table f]. Retrieved from http://www.nea.org/assets/docs/NEA-Rankings-and-Estimates-2013-2014.pdf

Rapee, R. M., Schniering, C. A., \& Hudson, J. L. (2009). Anxiety disorders during childhood and adolescence: Origins and treatment. Annual Review of Clinical Psychology, 5, 311-341. http://dx.doi.org/10.1146/annurev.clinpsy.032408.153628

Reinke, W. M., Stormont, M., Herman, K. C., Puri, R., \& Goel, N. (2011). Supporting children's mental health in schools: Teacher perceptions of needs, roles, and barriers. School Psychology Quarterly, 26, 1-13. http://dx.doi.org/10.1037/a0022714

Rockhill, C., Kodish, I., DiBattisto, C., Macias, M., Varley, C., \& Ryan, S. (2010). Anxiety disorders in children and adolescents. Current Problems in Pediatric and Adolescent Health Care, 40, 66-99. http://dx.doi.org/10.1016/j.cppeds.2010.02.002

Seligman, L. D., \& Ollendick, T. H. (2011). Cognitive behavioral therapy for anxiety disorders in youth. Child and Adolescent Psychiatric Clinics of North America, 20, 217-238. http://dx.doi.org/10.1016/j.chc.2011.01.003

Silverman, W. K., Pina, A. A., \& Viswesvaran, C. (2008). Evidence-based psychosocial treatments for phobic and anxiety disorders in children and adolescents. Journal of Clinical Child \& Adolescent Psychology, 37, 105-130. http://dx.doi.org/10.1080/15374410701817907

Singer, E., \& Ye, C. (2013). The use and effects of incentives in surveys. The Annals of the American Academy of Political and Social Science, 645, 112-141. http://dx.doi.org/10.1177/0002716212458082

Strein, W., Hoagwood, K., \& Cohn, A. (2003). School psychology: A public health perspective I: Prevention, populations, and systems change. Journal of School Psychology, 41, 23-38. http://dx.doi.org/10.1016/S0022-4405(02)00142-5

Suldo, S. M., \& Ogg, J. (2014). Best practices in interventions for anxiety-based school refusal. In P. L. Harrison, \& A. Thomas (Eds.), Best Practices in School Psychology: Student-level services (6th ed., pp. 365-380). Bethesda, MD: National Association of School Psychologists. 
Sulkowski, M. L., Joyce, D. K., \& Storch, E. A. (2012). Treating childhood anxiety in schools: Service delivery in response to intervention paradigm. Journal of Child and Family Studies, 21, 938-947. http://dx.doi.org/10.1007/s10826-011-9553-1

Whitley, J., Smith, D. J., \& Vaillancourt, T. (2012). Promoting mental health literacy among educators: Critical in school-based prevention and intervention. Canadian Journal of School Psychology, 28, 56-70. http://dx.doi.org/10.1177/0829573512468852

Wood, J. (2006). Effect of anxiety reduction on children's school performance and social adjustment. Developmental Psychology, 42, 345-349. http://dx.doi.org/10.1037/0012-1649.42.2.345

\section{Copyrights}

Copyright for this article is retained by the author(s), with first publication rights granted to the journal.

This is an open-access article distributed under the terms and conditions of the Creative Commons Attribution license (http://creativecommons.org/licenses/by/4.0/). 